\title{
Article \\ Statin Use Decreases the Risk of Metachronous Gastric Cancer in Patients without Helicobacter pylori Infection
}

\author{
Tae Jin Kwon ${ }^{\dagger}$, Tae Jun Kim ${ }^{\dagger}$, Hyuk Lee ${ }^{*} \mathbb{D}$, Yang Won Min, Byung-Hoon Min, Jun Haeng Lee and Jae J. Kim
}

check for

updates

Citation: Kwon, T.J.; Kim, T.J.; Lee, H.; Min, Y.W.; Min, B.-H.; Lee, J.H.; Kim, J.J. Statin Use Decreases the Risk of Metachronous Gastric Cancer in Patients without Helicobacter pylori Infection. Cancers 2021, 13, 1020. https://doi.org/10.3390/cancers 13051020

Academic Editor: Michele Valmasoni and Raquel Seruca

Received: 29 January 2021

Accepted: 22 February 2021

Published: 1 March 2021

Publisher's Note: MDPI stays neutral with regard to jurisdictional claims in published maps and institutional affiliations.

Copyright: (c) 2021 by the authors. Licensee MDPI, Basel, Switzerland. This article is an open access article distributed under the terms and conditions of the Creative Commons Attribution (CC BY) license (https:/ / creativecommons.org/licenses/by/ $4.0 /)$.
Department of Medicine, Samsung Medical Center, Sungkyunkwan University School of Medicine, 81 Irwon-ro, Gangnam-gu, Seoul 06351, Korea; tj6647.kwon@samsung.com (T.J.K.); tj23.kim@samsung.com (T.J.K.); yangwon.min@samsung.com (Y.W.M.); jason.min@samsung.com (B.-H.M.); jh2145.lee@samsung.com (J.H.L.); jaej.kim@samsung.com (J.J.K.)

* Correspondence: leehyuk@skku.edu; Tel.: +82-2-3410-3409; Fax: +82-2-3410-6983

+ These authors contributed equally to this work.

Simple Summary: Statins have been shown to reduce the risk of gastric cancer (GC). Little is known about their effects on metachronous GC in H. pylori negative patients after endoscopic resection for early gastric cancer (EGC). In this cohort study among patients with EGC without H. pylori infection, we found that statins are associated with a decrease in the risk of recurrence of GC. There was a dose-response relationship between the use of statins and the risk of metachronous GC. This study provides evidence about the additional benefits of statins as chemopreventive agents against metachronous GC among patients who underwent endoscopic resection for EGC.

Abstract: Previous studies have shown that statins reduce the risk of gastric cancer; however, their role has not been adequately studied in patients without Helicobacter pylori infection. We aimed to investigate whether statins reduced the risk of metachronous gastric cancer (GC) in H. pylori-negative patients who underwent endoscopic resection for early gastric cancer (EGC). Retrospective data of 2153 patients recruited between January 2007 and December 2016, with no H. pylori infection at baseline, who underwent resection for EGC, were analyzed. Metachronous GC was defined as a newly developed GC at least 1 year after endoscopic resection. Patients who used statins for at least 28 days during the follow-up period were considered as statin users. During a median follow-up of 5 years (interquartile range, 3.5-6.2), metachronous GC developed in 165 (7.6\%) patients. In the multivariate Cox regression analysis, statin use was an independent factor associated with GC recurrence (adjusted hazard ratio (HR), 0.46; 95\% confidence interval (CI), 0.26-0.82). Moreover, the risk of GC reduced with increasing duration (<3 years: HR $0.40,95 \%$ CI $0.14-1.13$; $\geq 3$ years: HR $0.21,95 \%$ CI $0.05-0.90 ; p$ trend $=0.011$ ) and the dose of statin (cumulative defined daily dose (cDDD) < 500: HR 0.45, 95\% CI 0.16-1.28; cDDD $\geq 500$ : HR 0.19, 95\% CI 0.04-0.80; $p$ trend $=0.008$ ) in the propensity score-matched cohort. Statin use was associated with a lower risk of GC recurrence in H. pylori-negative patients with resected EGC in a dose-response relationship.

Keywords: gastric cancer; ESD; statin; prevention

\section{Introduction}

Gastric cancer (GC) has the fifth highest incidence and is the third highest cause of cancer-related death globally [1,2]. Early gastric cancer (EGC) is defined as invasive GC confined of the mucosa and submucosa, irrespective of lymph node metastasis. Endoscopic resection as a minimally invasive treatment is indicated for EGC with a negligible risk of lymph node metastasis. However, metachronous GC, defined as a new GC located distant from the site of index GC after 1 year of index endoscopic resection, can develop due to the preservation of the stomach. Known risk factors for metachronous GC include Helicobacter pylori infection, age, male sex, and severe gastric mucosal atrophy $[3,4]$. H. pylori infection is the primary cause of gastric adenocarcinoma $[5,6]$. A recent meta-analysis reported 
that $H$. pylori eradication was associated with a $47 \%$ reduction in the risk of GC [7]. $H$. pylori eradication is also beneficial after the treatment of EGC [8]. In a recent randomized clinical trial of patients who underwent endoscopic resection for EGC, H. pylori eradication reduced the risk of metachronous GC by 50\% [9]. Since H. pylori eradication reduces the risk of metachronous GC by only about $50 \%$, there remains an unmet need to identify effective chemopreventive agents against GC.

Statins are widely used as cholesterol-lowering agents and are known to be competitive inhibitors of $\beta$-Hydroxy $\beta$-methylglutaryl-coenzyme A (HMG-CoA) reductase. Statins have been found to be associated with a decreased risk of various malignancies in numerous epidemiologic studies $[10,11]$. In addition to their cholesterol-lowering properties, statins also have antiproliferative and proapoptotic effects [12]. Although there are conflicting results about the benefit of statins in GC, in a case-control study of patients with diabetes from South Korea, statin use was associated with an $80 \%$ reduction in the likelihood of developing GC [13]. In contrast, a Dutch study with a pharmacy database found no significant association between statin use and GC [14]. Without stratifying the patients based on their H. pylori infection status, the true impact of statin use on the risk of GC cannot be conclusively analyzed. The chemopreventive effect of statins should be investigated in patients with no H. pylori infection to eliminate the effect of H. pylori infection as a confounding factor. In addition, it is necessary to confirm the effect of statins on the prevention of GC in high-risk patients.

To date, there are no studies that have investigated the chemopreventive effect of statins on metachronous GC in H. pylori-negative patients who have undergone resection for EGC. Therefore, we aimed to investigate the chemopreventive effect of statins on metachronous GC in a cohort of $H$. pylori-negative patients who underwent endoscopic resection for EGC.

\section{Results}

\subsection{Baseline Characteristics of the Study Cohort}

In this cohort, 228 patients were statin users, and 1925 patients were statin nonusers. Baseline characteristics of the subjects in both groups are summarized in Table 1. The median age of the study patients was 64 years [interquartile range (IQR), 57-71], and the total cohort of 2153 patients comprised $1699(78.9 \%)$ men and $454(21.1 \%)$ women. Statin users were more likely to take aspirin or metformin and had a higher proportion of patients with dyslipidemia, hypertension, diabetes mellitus, myocardial infarction, heart failure, chronic kidney disease, and cerebrovascular accident. However, there was no difference between statin users and nonusers in terms of age, sex, and tumor characteristics.

Table 1. Baseline characteristics of the study cohort.

\begin{tabular}{|c|c|c|c|c|}
\hline Variables & $\begin{array}{l}\text { Total Patients } \\
(\mathrm{N}=2153)\end{array}$ & $\begin{array}{l}\text { Statin Users } \\
(N=228)\end{array}$ & $\begin{array}{l}\text { Statin Nonusers } \\
(\mathrm{N}=1925)\end{array}$ & $p$ Value \\
\hline Age, year & $64(57-71)$ & $66(60-74)$ & $64(57-71)$ & $<0.001$ \\
\hline Male & $1699(78.9)$ & $195(85.5)$ & $1504(78.1)$ & 0.01 \\
\hline Tumor size, $\mathrm{mm}$ & $12(8-19)$ & $12(8-17)$ & $12(8-20)$ & 0.09 \\
\hline Tumor location & & & & 0.22 \\
\hline Lower & $1357(63.0)$ & $73(62.9)$ & $1224(63.6)$ & \\
\hline Middle & $749(34.8)$ & $42(36.2)$ & $658(34.2)$ & \\
\hline Upper & $47(2.2)$ & $1(0.9)$ & $43(2.2)$ & \\
\hline Tumor macroscopic type & & & & 0.003 \\
\hline Elevated & $270(12.5)$ & $27(11.8)$ & $243(12.6)$ & \\
\hline Flat & $310(14.4)$ & 45 (19.7) & $265(13.8)$ & \\
\hline Depressed & $1009(46.9)$ & $117(51.3)$ & $892(46.3)$ & \\
\hline Mixed & $564(26.2)$ & $39(17.1)$ & $525(27.3)$ & \\
\hline Depth of invasion & & & & 0.49 \\
\hline Mucosa (T1a) & $1963(91.2)$ & $212(93.0)$ & $1751(91.0)$ & \\
\hline Submucosa (T1b) & $190(8.8)$ & $16(7.0)$ & $174(9.0)$ & \\
\hline
\end{tabular}


Table 1. Cont.

\begin{tabular}{|c|c|c|c|c|}
\hline Variables & $\begin{array}{l}\text { Total Patients } \\
(\mathrm{N}=2153)\end{array}$ & $\begin{array}{l}\text { Statin Users } \\
(\mathrm{N}=228)\end{array}$ & $\begin{array}{l}\text { Statin Nonusers } \\
(\mathrm{N}=1925)\end{array}$ & $p$ Value \\
\hline Histologic differentiation & & & & 0.49 \\
\hline Differentiated & $2148(99.8)$ & $227(99.6)$ & $1921(99.8)$ & \\
\hline Undifferentiated & $5(0.2)$ & $1(0.4)$ & $4(0.2)$ & \\
\hline Histologic heterogeneity & & & & 0.40 \\
\hline Absent & $2011(93.4)$ & $210(92.1)$ & $1801(93.6)$ & \\
\hline Present & $142(6.6)$ & $18(7.9)$ & $124(6.4)$ & \\
\hline Lymphovascular invasion & $43(2.0)$ & $6(2.6)$ & $37(1.9)$ & 0.46 \\
\hline \multicolumn{5}{|l|}{ Comorbidities } \\
\hline Hypertension & $378(17.6)$ & $153(67.1)$ & $225(11.7)$ & $<0.001$ \\
\hline Diabetes mellitus & $240(11.1)$ & $96(42.1)$ & $144(7.5)$ & $<0.001$ \\
\hline Myocardial infarction & $32(1.5)$ & $17(7.5)$ & $15(0.8)$ & $<0.001$ \\
\hline Heart failure & $58(2.7)$ & $29(12.7)$ & $29(1.5)$ & $<0.001$ \\
\hline Chronic kidney disease & $87(4.0)$ & $40(17.5)$ & $47(2.4)$ & $<0.001$ \\
\hline Liver cirrhosis & $56(2.6)$ & $8(3.5)$ & $48(2.5)$ & 0.36 \\
\hline Cerebrovascular accident & $206(9.6)$ & $87(38.2)$ & $119(6.2)$ & $<0.001$ \\
\hline Comorbidities $(\geq 2)$ & $380(17.6)$ & $200(87.8)$ & $180(10.4)$ & $<0.001$ \\
\hline Aspirin & $252(11.7)$ & $132(57.8)$ & $120(6.2)$ & $<0.001$ \\
\hline Metformin & $199(9.2)$ & $57(25.6)$ & $142(7.4)$ & $<0.001$ \\
\hline
\end{tabular}

Values are expressed as median (interquartile range) or frequency (percentage).

\subsection{Factors Associated with Metachronous GC}

During a median follow-up of 5 years (IQR, 3.5-6.2), metachronous GC developed in $165(7.6 \%)$ patients. Among 165 patients who developed metachronous GC, 13 patients were statin users, and 152 patients were nonusers. Statin users showed a significantly lower cumulative incidence of metachronous GC compared with statin nonusers (Log-rank $p$ value $=0.015$, Figure $1 \mathrm{~A}$ ). When limited to 5 years, it was not statistically significant (Log-rank $p$ value $=0.1$, Figure 1B), but, when limited to 8 years, there was a significant difference in incidence of metachronous GC (Log-rank $p$ value $=0.018$, Figure 1C). In the univariate analysis, statin use was associated with a lower risk of metachronous GC (hazard ratio (HR), 0.50; 95\% confidence interval (CI), 0.28-0.85); in contrast, age was associated with the development of metachronous GC (Table 2). In the multivariate analysis, statin use was independently associated with a lower risk of metachronous GC (HR, 0.46; 95\% $\mathrm{CI}, 0.26-0.82)$. Age was the only factor associated with a higher risk of metachronous GC (HR, 1.03; 95\% CI, 1.01-1.05).
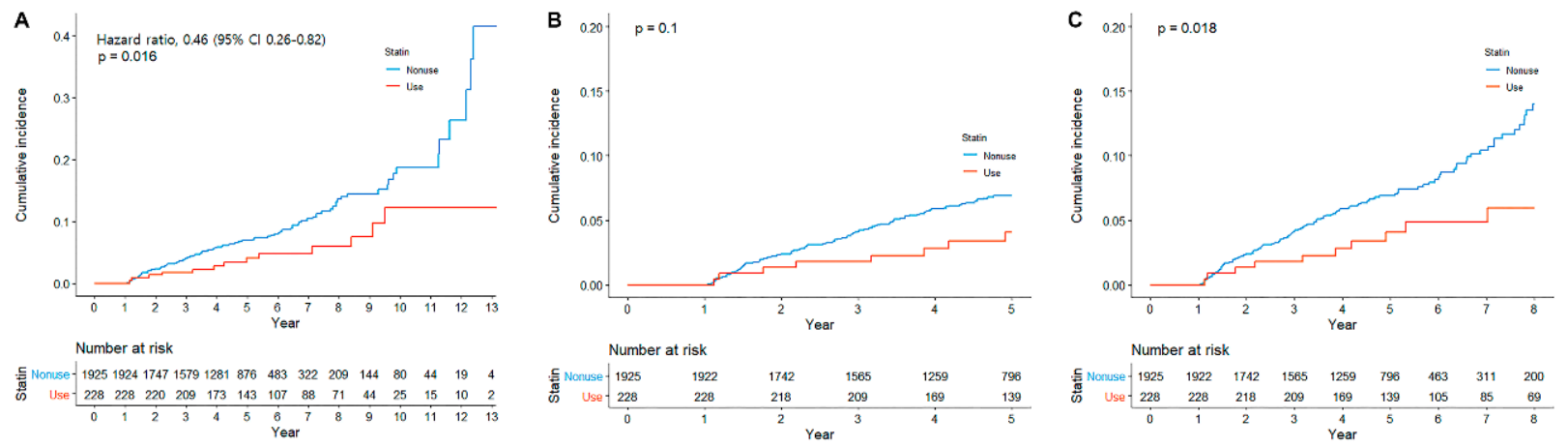

Figure 1. Cumulative incidence of metachronous gastric cancer according to statin use, (A) overall, (B) until 5 years, and (C) until 8 years. 
Table 2. Factors associated with metachronous gastric cancer.

\begin{tabular}{|c|c|c|c|c|}
\hline \multirow{2}{*}{ Factors } & \multicolumn{2}{|c|}{ Univariable Analysis } & \multicolumn{2}{|c|}{ Multivariable Analysis } \\
\hline & HR $(95 \%$ CI) & $p$ Value & HR $(95 \%$ CI) & $p$ Value \\
\hline Age (per year) & $1.03(1.01-1.05)$ & $<0.001$ & $1.03(1.02-1.05)$ & $<0.001$ \\
\hline Male sex & $1.20(0.86-1.79)$ & 0.36 & & \\
\hline Tumor size, $\mathrm{mm}$ & $1.01(0.99-1.02)$ & 0.07 & $1.005(0.99-1.02)$ & 0.505 \\
\hline \multicolumn{5}{|l|}{ Tumor location } \\
\hline Lower & Reference & & Reference & \\
\hline Middle & $1.32(0.96-1.81)$ & 0.08 & $1.35(0.99-1.85)$ & 0.056 \\
\hline Upper & $1.06(0.033-3.34)$ & 0.92 & $0.93(0.29-2.95)$ & 0.91 \\
\hline \multicolumn{5}{|l|}{ Tumor macroscopic type } \\
\hline Elevated & Reference & & Reference & \\
\hline Flat & $0.70(0.42-1.25)$ & 0.23 & $0.75(0.42-1.33)$ & 0.33 \\
\hline Depressed & $0.64(0.40-1.02)$ & 0.06 & $0.74(0.47-1.19)$ & 0.22 \\
\hline Mixed & $0.91(0.56-1.48)$ & 0.72 & $0.98(0.60-1.58)$ & 0.93 \\
\hline \multicolumn{5}{|l|}{ Depth of invasion } \\
\hline Mucosa (T1a) & Reference & & & \\
\hline Submucosa (T1b) & $1.00(0.60-1.69)$ & 0.97 & & \\
\hline \multicolumn{5}{|l|}{ Histologic differentiation } \\
\hline Differentiated & Reference & & & \\
\hline Undifferentiated & $0.05(0-)$ & 0.66 & & \\
\hline \multicolumn{5}{|l|}{ Histologic heterogeneity } \\
\hline Absent & Reference & & & \\
\hline Present & $1.49(0.89-2.49)$ & 0.12 & & \\
\hline Lymphovascular invasion & $1.44(0.53-3.89)$ & 0.46 & & \\
\hline \multicolumn{5}{|l|}{ Comorbidities } \\
\hline Hypertension & $0.85(0.58-1.26)$ & 0.44 & & \\
\hline Diabetes mellitus & $1.19(0.76-1.85)$ & 0.38 & & \\
\hline Myocadiac infarction & $0.67(0.16-2.73)$ & 0.58 & & \\
\hline Heart failure & $1.07(0.47-2.42)$ & 0.87 & & \\
\hline Chronic kidney disease & $0.97(0.47-1.98)$ & 0.93 & & \\
\hline Liver cirrhosis & $1.16(0.51-2.62)$ & 0.72 & & \\
\hline Cerebrovascular disease & $1.03(0.64-1.67)$ & 0.87 & & \\
\hline Statin use & $0.50(0.28-0.85)$ & 0.017 & $0.46(0.26-0.82)$ & 0.008 \\
\hline Aspirin use & $1.21(0.80-1.82)$ & 0.35 & & \\
\hline Metformin use & $1.37(0.85-2.21)$ & 0.19 & & \\
\hline
\end{tabular}

HR, hazard ratio; CI, confidence interval.

\subsection{Duration and Dose-Response Effects of Statin Use on the Occurrence of Metachronous GC}

Table 3 shows the duration and dose-response effects of statin use on the occurrence of metachronous GC. The HRs (95\% CIs) of metachronous GC in subjects who used statins for less than 2 years, $2-4$ years, and 4 years or more were 0.87 (0.41-1.87), $0.48(0.15-1.51)$, and $0.25(0.08-0.79)$, respectively, compared to the statin nonusers. In the dose-response effect analysis using cumulative defined daily dose (cDDD), the HRs (95\% CIs) of metachronous GC with statin use $<500$ cDDD, 500-1000 cDDD, and $>1000$ cDDD were 0.91 (0.46-1.79), $0.64(0.20-2.01)$, and $0.08(0.01-0.58)$, respectively, compared to those of statin nonusers. In the propensity-score matching cohort (Table 4$)$, a significant inverse dose-response relationship was also observed between statin use and metachronous GC (<500 cDDD: HR 0.63, 95\% CI 0.27-1.48; 500-1000 cDDD: HR 0.39, 95\% CI 0.09-1.60; >1000 cDDD: HR 0.09, $95 \%$ CI $0.01-1.62)$. 
Table 3. Association between duration of use and dose of statins and gastric cancer.

\begin{tabular}{lll}
\hline \multirow{2}{*}{ Factors } & Multivariable Analysis ${ }^{\text {a }}$ & \\
\cline { 2 - 3 } & HR $\mathbf{( 9 5 \%}$ CI) & $p$ Value \\
\hline Duration & & \\
$\quad$ Non-statin use & Reference & \\
$\quad<2$ years & $0.87(0.41-1.87)$ & 0.73 \\
$\quad$ 2-4 years & $0.48(0.15-1.51)$ & 0.21 \\
$\quad$ 4 year & $0.25(0.08-0.79)$ & 0.019 \\
cDDD & & \\
$\quad$ Non-statin use & Reference & 0.79 \\
$\quad<500$ & $0.91(0.46-1.79)$ & 0.44 \\
$\quad$ 500-1000 & $0.64(0.20-2.01)$ & 0.013 \\
$\quad>1000$ & $0.08(0.01-0.58)$ & \\
a Estimated from Cox proportional hazard models adjusted for variables with a $p$ value $<0.10$ in the univariate \\
analysis. HR, hazard ratio; CI, confidence interval; cDDD, cumulative defined daily dose.
\end{tabular}

Table 4. Association between duration of use and dose of statins and gastric cancer in the propensity score-matched cohort.

\begin{tabular}{lll}
\hline Factors & HR $(\mathbf{9 5} \% \mathbf{C I})$ & $p$ Value \\
\hline Statin use & $0.34(0.17-0.71)$ & 0.004 \\
Duration & Reference & \\
$\quad$ Non-statin use & $0.57(0.23-1.44)$ & 0.235 \\
$\quad<2$ years & $0.31(0.07-1.27)$ & 0.104 \\
$\quad$ 2-4 years & $0.18(0.04-0.75)$ & 0.018 \\
$\quad>4$ year & & \\
CDDD & Reference & \\
$\quad$ Non-statin use & $0.63(0.27-1.48)$ & 0.286 \\
$\quad<500$ & $0.39(0.09-1.60)$ & 0.191 \\
$\quad 500-1000$ & $0.09(0.01-0.62)$ & 0.015 \\
$\quad>1000$ &
\end{tabular}

\section{Discussion}

In this cohort study of H. pylori-negative patients who underwent endoscopic resection for EGC, we found that statin use was associated with a significant decrease in the risk of GC. Furthermore, significant dose and duration-response effects were observed among patients with a high risk of GC. Since the risk of metachronous GC is high (5-year rate, $3.6 \%$ to $16 \%$ ) [15-21] in patients who undergo endoscopic resection for EGC, eradication of $H$. pylori could reduce the risk of metachronous GC in patients with $H$. pylori infection [9]. In addition, there is a need to develop novel chemopreventive agents for high-risk patients of GC without $H$. pylori infection.

Previous studies have examined the chemopreventive role of statins in GC; however, the results have been inconsistent [13,22-26]. Randomized controlled trials (RCTs), which included post-hoc analyses for identifying the effect of statins on cardiovascular disease, did not show a chemopreventive effect of statins on the risk of GC, though they found a statistically significant trend (adjusted odds ratio, 0.83 ; 95\% CI, 0.66-1.05) [22,25]. However, the follow-up duration in these studies was not long enough, and the patients were not at a high risk of GC. The chemopreventive effect of statins has been seen in observational studies. A population-based case-control study in Taiwan found that the use of any statin was associated with a lower risk of GC [24]. Another case-control study found that longer the duration of statin use lower was the risk for GC [13]. However, since it was a retrospective case-control study, patients were not routinely screened for GC. The reduced risk of GC observed in statin users might thus be related to the 'healthy user' bias [27]. A recent Korean population-based cohort study demonstrated that the use of statin was associated with a reduced risk of metachronous GC in patients who underwent 
endoscopic resection for EGC [23]. However, the major limitation of the study was the failure to evaluate the status of $H$. pylori infection.

A major limitation of previous studies was the failure to evaluate the status of $H$. pylori infection. A previous meta-analysis of 11 studies found that the use of statin was associated with a reduced risk of GC; however, the included studies did not consider $H$. pylori infection, which is closely related to the risk of GC [25]. A recent study included only patients who were prescribed clarithromycin-based triple therapy for the eradication of H. pylori; however, the data of post-treatment $H$. pylori status were unavailable [26]. Since the H. pylori eradication rates with clarithromycin triple therapy are reported to be $70-85 \%$, based on the underlying rate of clarithromycin resistance [28], the study might have included patients with persistent $H$. pylori infection. In this study, we evaluated the H. pylori status of all patients through a consistent standard method at baseline. Therefore, we included only patients without $H$. pylori infection in the analysis. In addition, a Cox regression analysis adjusted for host factor, detailed tumor characteristics, and important comorbidities, as well as a propensity score matching analysis, were performed to eliminate the potential confounding factors and to minimize the differences between statin users and nonusers. A homogenous cohort, rigorous control of the critical confounders for GC, and a cohort design with annual endoscopic surveillance are the data that provide additional support for the causal relationship between statin use and GC development.

There are several plausible mechanisms to explain the association between statin use and the risk of GC. Large RCTs that analyzed the preventive effects of statins on cardiovascular disease indicated that statins had additional benefits in terms of a decrease in the incidence of colorectal, breast, prostate, and skin cancer [29-32]. In addition to the HMG-CoA-dependent effect, which is the main mechanism of action of statins, they have important cholesterol/HMG-CoA-independent effects, such as the effect on lymphocytefunction-associated antigen 1 and inhibition of geranylgeranylation, primarily of Rho proteins. These effects that inhibit carcinogenesis involving inflammation, immunomodulation, and angiogenesis are thought to potentially contribute to cancer prevention [33]. In addition, GC is genetically heterogenous disease that progresses through different carcinogenic pathways. Among the genetic changes associated with multi-stage carcinogenesis, C-myc, c-erbB2, K-ras, C-met, TP53, APC, and RUNX3 have been reported [34]. In mice models, inhibition of HMG-CoA reductase by statin inhibits tumor initiation and growth by blocking MYC phosphorylation and activation [35]. In a study using human HGT-1 GC cell line, statin suppressed expression of genes involved in cell division and induced apoptosis of cancer cells overexpressing the MDR-1 gene [36].

Several limitations need to be considered in interpreting these data. First, the histologic examination with special staining methods, such as Giemsa, has been regarded as the gold standard in identifying $H$. pylori infection, with known sensitivity and specificity reaching $95 \%$ and $98 \%$, respectively [37]. Although our data might include false negatives, we focused on the effect of statins in the absence of the chemopreventive intervention of H. pylori eradication; thus, these would not have affected the results. Second, there might be potential for an inherent selection bias since this was a retrospective observational study. Therefore, a propensity score matching was performed to minimize the differences in the patients' characteristics between statin users and nonusers. Since this study was conducted in a single-center, surveillance endoscopy was regularly performed at least once a year after endoscopic resection in all patients. There was also no difference in the surveillance interval between statin users and nonusers. Third, although we adjusted for potential confounders, there is still a likelihood of unmeasured residual confounding, such as that caused by smoking, family history of GC, and dietary factors due to the observational nature of our study design. Fourth, a previous study showed that low serum cholesterol levels were an independent risk factor for developing GC [38]; however, our data did not include cholesterol levels. Although the main anticancer effect of statin is explained by cholesterol/HMG-CoA-independent effects rather than the cholesterol-lowering effect, further evaluation is necessary for the effect of changes in cholesterol levels during statin 
use on the recurrence of GC. Fifth, only Korean patients were included in this study. Koreans have a higher risk of GC than the western populations. Although the results of this study support the effect of statins as chemopreventive agents on GC, external validation in other ethnic groups is necessary to assess the risk-benefit ratio of statins for the prevention of GC.

In conclusion, this study showed that statin use was associated with a significantly lower risk of metachronous GC among high-risk patients without $H$. pylori infection in a dose-and duration-dependent manner. Further prospective studies are needed to confirm this association.

\section{Materials and Methods}

\subsection{Study Design and Patient Selection}

We performed a hospital-based retrospective cohort study of patients who underwent endoscopic resection for EGC at the Samsung Medical Center, Seoul, South Korea. Patients were considered eligible if they were $\geq 20$ years old and had undergone endoscopic resection for EGC between January 2007 and December $2016(n=4351)$ and followed up until 30 April 2020 (Figure 2). Patients who met any of the following criteria were excluded ( $n=2505)$ : (i) H. pylori infection at the index date $(n=1445)$; (ii) a history of gastrectomy before the index date or during the follow-up period $(n=496)$; and (iii) follow-up duration of less than 1 year $(n=257)$. Finally, a total of 2153 patients without $H$. pylori infection at baseline who underwent endoscopic resection for EGC and were followed up for more than 1 year were included. $H$. pylori infection status was examined routinely during endoscopy at 8 weeks after endoscopic resection for EGC in our center. H. pylori infection was evaluated by Giemsa staining of the sample tissues obtained from both the gastric antrum and body. The study protocol was approved by the Institutional Review Board of Samsung Medical Center. As the study used only de-identified data routinely collected during hospital visits, the requirement to obtain informed patient consent was waived.

4351 patients who had undergone endoscopic submucosal dissection for early gastric cancer in January 1, 2007 to December 31, 2016

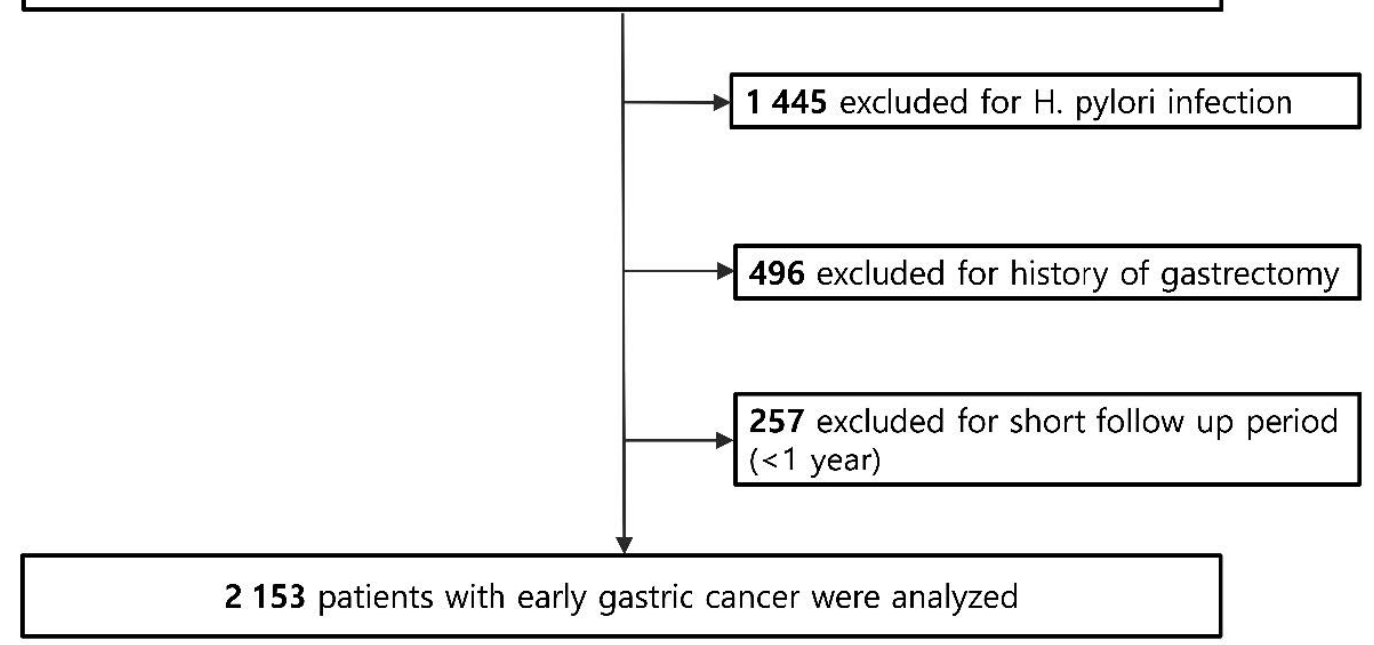

Figure 2. Flowchart of patient enrollment.

\subsection{Study Outcomes}

The primary outcome was the incidence of metachronous gastric adenocarcinoma confirmed by endoscopic biopsy. The index date was defined as the date of endoscopic resection for EGC. Metachronous GC was defined as a newly developed GC at least 1 year after the index date. Surveillance endoscopy is routinely performed at least once a year 
after endoscopic resection for EGC at our institution. The observation period started from the index date and ended when a metachronous GC was diagnosed or at the last clinic visit.

\subsection{Statin Exposure}

We collected the data of statin prescriptions during the follow-up period from our electronic medical record system. We identified the date of prescription, the daily dose, the number of days the drug was given, and the number of pills per statin prescription. Statins included simvastatin, atorvastatin, rosuvastatin, pitavastatin, pravastatin, and fluvastatin.

We defined statin use as at least a 28-day use after the index date. To examine the duration-response relationship, the duration of statin use was divided into four groups: no use, and $<2$ years, $2-4$ years, and $\geq 4$ years of use. To examine the dose-response relationship, the cumulative defined daily dose (cDDD), which is the total of the doses of different statins according to the World Health Organization, was used. The cDDD was calculated as the sum of DDD during the follow-up period. We divided patients into four groups according to the cDDD (no use, and $<500,500-1000$, and $>1000 \mathrm{mg}$ cDDD).

\subsection{Covariates}

Variables collected were age at index visit, sex, comorbidities (including hypertension, diabetes mellitus, dyslipidemia, cerebrovascular disease, myocardial infarction, heart failure, liver cirrhosis, and chronic kidney disease), and characteristics of index EGC. The characteristics of index EGC included tumor location, maximum size, morphology (elevated, flat, or depressed according to the Paris classification; mixed type), depth of invasion (mucosa or submucosa-invasive), lymphatic or venous invasion, degree of differentiation (based on the World Health Organization's Classification), and histologic heterogeneity.

\subsection{Statistical Analysis}

Descriptive statistics were used to summarize the patients' baseline characteristics according to statin use. The cumulative incidences of metachronous GC were evaluated using a Kaplan-Meier curve, and the difference between the curves was tested using the log-rank test. We used a Cox proportional hazard model to estimate the adjusted $\mathrm{HR}$ and $95 \% \mathrm{CI}$ for the development of metachronous GC according to statin use. Age, sex, comorbidities, and tumor characteristics (size, location, morphology, depth of invasion, lymphovascular invasion, histologic differentiation, and histologic heterogeneity) were considered as potential confounders for the association between statin use and metachronous GC. After performing the univariate analysis of each of the potential risk factors for metachronous GC, the variables with a $p$ value $<0.1$ in the univariate analysis were included in the multivariate analysis. To analyze the dose/duration effect of statin use on the risk of metachronous GC, we used cDDD/duration to assess the risk reduction and compare the risk to that of statin nonusers.

Additionally, propensity score matching was performed using multivariable logistic regression based on the aforementioned covariates to control the selection bias due to different baseline characteristics. Propensity score matching was performed using the nearest-neighbor matching method. The matching balance was evaluated as acceptable if the absolute value of the standardized mean difference was $<0.1$. After 1:3 propensity score matching, the baseline characteristics between statin users and nonusers were analyzed using a generalized estimating equation (Table 5). A $p$-value $<0.05$ was considered statistically significant. All statistical analyses were performed using $R$ version 3.4.3 ( $R$ Foundation for Statistical Computing, Vienna, Austria). 
Table 5. Baseline characteristics of the propensity score-matched cohort (1:3).

\begin{tabular}{|c|c|c|c|}
\hline Variables & $\begin{array}{l}\text { Statin Users } \\
(n=197)\end{array}$ & $\begin{array}{l}\text { Statin Nonusers } \\
(n=425)\end{array}$ & $p$ Value \\
\hline Age, year & $66(59-73)$ & $65(58-72)$ & 0.788 \\
\hline Male & $168(85.3)$ & $339(79.8)$ & 0.124 \\
\hline Tumor size, mm & $12(8-18)$ & $12(8-19)$ & 0.671 \\
\hline Tumor location & & & 0.960 \\
\hline Lower & $117(59.4)$ & $248(58.4)$ & \\
\hline Middle & $77(39.1)$ & $171(40.2)$ & \\
\hline Upper & $3(1.5)$ & $6(1.4)$ & \\
\hline Tumor macroscopic type & & & 0.830 \\
\hline Elevated & 45 (10.6) & 45 (10.6) & \\
\hline Flat & 79 (18.7) & 79 (18.6) & \\
\hline Depressed & $212(49.9)$ & $212(49.9)$ & \\
\hline Mixed & $89(20.9)$ & $89(20.9)$ & \\
\hline Depth of invasion & & & 0.763 \\
\hline Mucosa (T1a) & $182(92.4)$ & $388(91.3)$ & \\
\hline Submucosa (T1b) & $15(7.6)$ & $37(8.7)$ & \\
\hline Histologic differentiation & & & 0.936 \\
\hline Differentiated & $196(99.5)$ & $421(99.1)$ & \\
\hline Undifferentiated & $1(0.5)$ & $4(0.9)$ & \\
\hline Histologic heterogeneity & & & 0.802 \\
\hline Absent & $184(93.4)$ & $393(92.5)$ & \\
\hline Present & $13(6.6)$ & $32(7.5)$ & \\
\hline Lymphovascular invasion & $6(3.0)$ & $10(2.4)$ & 0.814 \\
\hline \multicolumn{4}{|l|}{ Comorbidities } \\
\hline Hypertension & $92(46.7)$ & $166(39.1)$ & 0.174 \\
\hline Diabetes mellitus & $49(24.9)$ & $100(23.5)$ & 0.860 \\
\hline Myocadiac infarction & $10(5.1)$ & $15(3.5)$ & 0.427 \\
\hline Heart failure & $16(8.1)$ & $26(6.1)$ & 0.423 \\
\hline Chronic kidney disease & $27(13.7)$ & $38(8.9)$ & 0.110 \\
\hline Liver cirrhosis & $8(4.1)$ & $16(3.8)$ & 1.000 \\
\hline Cerebrovascular disease & $61(31.0)$ & $107(25.2)$ & 0.145 \\
\hline
\end{tabular}

Values are expressed as median (interquartile range) or frequency (percentage).

\section{Conclusions}

Statin use was associated with a significantly lower risk of metachronous GC among high-risk patients without $H$. pylori infection in a dose- and duration-dependent manner. This finding provides evidence about the additional benefits of statin as chemopreventive agents against metachronous GC among patients who underwent endoscopic resection for EGC. Further prospective studies are required to confirm this association and evaluate risk-benefit in practical use.

Author Contributions: Study concept and design: H.L. Acquisition, analysis, or interpretation of data: T.J.K. (Tae Jin Kwon) and T.J.K. (Tae Jun Kim). Writing and Drafting of the manuscript: T.J.K. (Tae Jin Kwon) and T.J.K. (Tae Jun Kim). Critical revision of the manuscript for important intellectual content: Y.W.M., H.L., B.-H.M., J.H.L. and J.J.K. All authors have read and agreed to the published version of the manuscript.

Funding: This research received no external funding.

Institutional Review Board Statement: The study was conducted according to the guidelines of the Declaration of Helsinki, and approved by the Institutional Review Board of Samsung Medical Center (IRB No. SMC 2020-08-116, 1 September 2020).

Informed Consent Statement: The requirement for informed consent was waived because of the retrospective nature of this study.

Data Availability Statement: The data presented in this study are available on request from the corresponding author. The data are not publicly available due to privacy and ethical restrictions. 
Conflicts of Interest: The authors disclose no conflict of interest.

\section{References}

1. Bray, F.; Ferlay, J.; Soerjomataram, I.; Siegel, R.L.; Torre, L.A.; Jemal, A. Global cancer statistics 2018: GLOBOCAN estimates of incidence and mortality worldwide for 36 cancers in 185 countries. CA Cancer J. Clin. 2018, 68, 394-424. [CrossRef]

2. Thrift, A.P.; El-Serag, H.B. Burden of Gastric Cancer. Clin. Gastroenterol. Hepatol. 2020, 18, 534-542. [CrossRef]

3. Maehata, Y.; Nakamura, S.; Fujisawa, K.; Esaki, M.; Moriyama, T.; Asano, K.; Fuyuno, Y.; Yamaguchi, K.; Egashira, I.; Kim, H.; et al. Long-term effect of Helicobacter pylori eradication on the development of metachronous gastric cancer after endoscopic resection of early gastric cancer. Gastrointest. Endosc. 2012, 75, 39-46. [CrossRef] [PubMed]

4. Kwon, Y.H.; Heo, J.; Lee, H.S.; Cho, C.M.; Jeon, S.W. Failure ofHelicobacter pylorieradication and age are independent risk factors for recurrent neoplasia after endoscopic resection of early gastric cancer in 283 patients. Aliment. Pharmacol. Ther. 2014, 39, 609-618. [CrossRef]

5. Correa, P.; Piazuelo, M.B.; Camargo, M.C. The future of gastric cancer prevention. Gastric Cancer 2004, 7, 9-16. [CrossRef]

6. A Helicobacter and Cancer Collaborative Group Gastric cancer and Helicobacter pylori: A combined analysis of 12 case control studies nested within prospective cohorts. Gut 2001, 49, 347-353. [CrossRef] [PubMed]

7. Lee, Y.-C.; Chiang, T.-H.; Chou, C.-K.; Tu, Y.-K.; Liao, W.-C.; Wu, M.-S.; Graham, D.Y. Association Between Helicobacter pylori Eradication and Gastric Cancer Incidence: A Systematic Review and Meta-analysis. Gastroenterol. 2016, 150, 1113-1124. [CrossRef]

8. Bae, S.E.; Jung, H.-Y.; Kang, J.; Park, Y.S.; Baek, S.; Jung, J.-H.; Choi, J.Y.; Kim, M.-Y.; Ahn, J.Y.; Choi, K.-S.; et al. Effect of Helicobacter pylori Eradication on Metachronous Recurrence After Endoscopic Resection of Gastric Neoplasm. Am. J. Gastroenterol. 2014, 109, 60-67. [CrossRef] [PubMed]

9. Choi, I.J.; Kook, M.-C.; Kim, Y.-I.; Cho, S.-J.; Lee, J.Y.; Kim, C.G.; Park, B.; Nam, B.-H. Helicobacter pylori Therapy for the Prevention of Metachronous Gastric Cancer. N. Engl. J. Med. 2018, 378, 1085-1095. [CrossRef]

10. Boudreau, D.M.; Yu, O.; Johnson, J. Statin use and cancer risk: A comprehensive review. Expert Opin. Drug Saf. 2010,9 , 603-621. [CrossRef] [PubMed]

11. Singh, S.; Singh, A.G.; Singh, P.P.; Murad, M.H.; Iyer, P.G. Statins Are Associated With Reduced Risk of Esophageal Cancer, Particularly in Patients With Barrett's Esophagus: A Systematic Review and Meta-analysis. Clin. Gastroenterol. Hepatol. 2013, 11, 620-629. [CrossRef]

12. Pisanti, S.; Picardi, P.; Ciaglia, E.; D'Alessandro, A.; Bifulco, M. Novel prospects of statins as therapeutic agents in cancer. Pharmacol. Res. 2014, 88, 84-98. [CrossRef] [PubMed]

13. Lee, J.; Lee, S.H.; Hur, K.Y.; Woo, S.Y.; Kim, S.W.; Kang, W.K. Statins and the risk of gastric cancer in diabetes patients. BMC Cancer 2012, 12, 596. [CrossRef]

14. Graaf, M.R.; Beiderbeck, A.B.; Egberts, A.C.G.; Richel, D.J.; Guchelaar, H.-J. The Risk of Cancer in Users of Statins. J. Clin. Oncol. 2004, 22, 2388-2394. [CrossRef]

15. Abe, S.; Oda, I.; Suzuki, H.; Nonaka, S.; Yoshinaga, S.; Nakajima, T.; Sekiguchi, M.; Mori, G.; Taniguchi, H.; Sekine, S.; et al. Long-term surveillance and treatment outcomes of metachronous gastric cancer occurring after curative endoscopic submucosal dissection. Endoscopy 2015, 47, 1113-1118. [CrossRef] [PubMed]

16. Kato, M.; Nishida, T.; Yamamoto, K.; Hayashi, S.; Kitamura, S.; Yabuta, T.; Yoshio, T.; Nakamura, T.; Komori, M.; Kawai, N.; et al. Scheduled endoscopic surveillance controls secondary cancer after curative endoscopic resection for early gastric cancer: A multicentre retrospective cohort study by Osaka University ESD study group. Gut 2012, 62, 1425-1432. [CrossRef]

17. Min, B.-H.; Kim, E.R.; Kim, K.-M.; Park, C.K.; Lee, J.H.; Rhee, P.-L.; Kim, J.J. Surveillance strategy based on the incidence and patterns of recurrence after curative endoscopic submucosal dissection for early gastric cancer. Endoscopy 2015, 47, 784-793. [CrossRef]

18. Pyo, J.H.; Lee, H.; Min, B.-H.; Lee, J.H.; Choi, M.G.; Sohn, T.S.; Bae, J.M.; Kim, K.M.; Ahn, J.H.; Carriere, K.C.; et al. Long-Term Outcome of Endoscopic Resection vs. Surgery for Early Gastric Cancer: A Non-inferiority-Matched Cohort Study. Am. J. Gastroenterol. 2016, 111, 240-249. [CrossRef] [PubMed]

19. Ryu, S.J.; Kim, B.-W.; Kim, B.G.; Kim, J.H.; Kim, J.S.; Park, J.-M.; Oh, J.-H.; Kim, T.H.; Park, S.-M.; Park, C.H.; et al. Endoscopic submucosal dissection versus surgical resection for early gastric cancer: A retrospective multicenter study on immediate and long-term outcome over 5 years. Surg. Endosc. 2016, 30, 5283-5289. [CrossRef]

20. Park, C.H.; Lee, H.; Kim, D.W.; Chung, H.; Park, J.C.; Shin, S.K.; Hyung, W.J.; Kil Lee, S.; Lee, Y.C.; Noh, S.H. Clinical safety of endoscopic submucosal dissection compared with surgery in elderly patients with early gastric cancer: A propensity-matched analysis. Gastrointest. Endosc. 2014, 80, 599-609. [CrossRef]

21. Choi, I.J.; Lee, J.H.; Kim, Y.-W.; Kim, C.G.; Cho, S.-J.; Lee, J.Y.; Ryu, K.W.; Nam, B.-H.; Kook, M.-C. Long-term outcome comparison of endoscopic resection and surgery in early gastric cancer meeting the absolute indication for endoscopic resection. Gastrointest. Endosc. 2015, 81, 333-341.e1. [CrossRef] [PubMed]

22. Cholesterol Treatment Trialists' (CTT) Collaboration Lack of Effect of Lowering LDL Cholesterol on Cancer: Meta-Analysis of Individual Data from 175,000 People in 27 Randomised Trials of Statin Therapy. PLoS ONE 2012, 7, e29849. [CrossRef]

23. Chung, H.; Kim, H.J.; Jung, H.C.; Kil Lee, S.; Kim, S.G. Statins and metachronous recurrence after endoscopic resection of early gastric cancer: A nationwide Korean cohort study. Gastric Cancer 2020, 23, 659-666. [CrossRef] 
24. Chiu, H.-F.; Ho, S.-C.; Chang, C.-C.; Wu, T.-N.; Yang, C.-Y. Statins Are Associated With a Reduced Risk of Gastric Cancer: A Population-Based Case-Control Study. Am. J. Gastroenterol. 2011, 106, 2098-2103. [CrossRef] [PubMed]

25. Singh, P.; Singh, S. Statins are associated with reduced risk of gastric cancer: A systematic review and meta-analysis. Ann. Oncol. 2013, 24, 1721-1730. [CrossRef]

26. Cheung, K.S.; Chan, E.W.; Wong, A.Y.S.; Chen, L.; Seto, W.-K.; Wong, I.C.K.; Leung, W.K. Statins were associated with a reduced gastric cancer risk in patients with eradicated Helicobacter pylori infection: A territory-wide propensity score matched study. Cancer Epidemiol. Biomark. Prev. 2019, 29, 493-499. [CrossRef]

27. Patrick, A.R.; Shrank, W.H.; Glynn, R.J.; Solomon, D.H.; Dormuth, C.R.; Avorn, J.; Cadarette, S.M.; Mogun, H.; Brookhart, M.A. The Association between Statin use and Outcomes Potentially Attributable to an Unhealthy Lifestyle in Older Adults. Value Heal. 2011, 14, 513-520. [CrossRef]

28. Chey, W.D.; Wong, B.C.Y. Practice Parameters Committee of the American College of Gastroenterology American College of Gastroenterology Guideline on the Management of Helicobacter pylori Infection. Am. J. Gastroenterol. 2007, 102, $1808-1825$. [CrossRef]

29. Newman, T.B.; Hulley, S.B. Carcinogenicity of Lipid-Lowering Drugs. JAMA 1996, 275, 55. [CrossRef]

30. Oliver, M. Might treatment of hypercholesterolaemia increase non-cardiac mortality? Lancet 1991, 337, 1529-1531. [CrossRef]

31. Ridker, P.M.; Rifai, N.; Pfeffer, M.A.; Sacks, F.M.; Moye, L.A.; Goldman, S.; Flaker, G.C.; Braunwald, E. Inflammation, Pravastatin, and the Risk of Coronary Events After Myocardial Infarction in Patients With Average Cholesterol Levels. Circulation 1998, 98, 839-844. [CrossRef] [PubMed]

32. Gazzerro, P.; Bifulco, M. Statins and Cancer in Gastroenterology: New Insight? Gastroenterol. 2013, 144, 1572-1573. [CrossRef] [PubMed]

33. Demierre, M.-F.; Higgins, P.D.R.; Gruber, S.B.; Hawk, E.T.; Lippman, S.M. Statins and cancer prevention. Nat. Rev. Cancer 2005, 5, 930-942. [CrossRef] [PubMed]

34. Panani, A.D. Cytogenetic and molecular aspects of gastric cancer: Clinical implications. Cancer Lett. 2008, 266, 99-115. [CrossRef]

35. Cao, Z.; Fan-Minogue, H.; Bellovin, D.I.; Yevtodiyenko, A.; Arzeno, J.; Yang, Q.; Gambhir, S.S.; Felsher, D.W. MYC Phosphorylation, Activation, and Tumorigenic Potential in Hepatocellular Carcinoma Are Regulated by HMG-CoA Reductase. Cancer Res. 2011, 71, 2286-2297. [CrossRef]

36. Follet, J.; Corcos, L.; Baffet, G.; Ezan, F.; Morel, F.; Simon, B.; Le Jossic-Corcos, C. The association of statins and taxanes: An efficient combination trigger of cancer cell apoptosis. Br. J. Cancer 2012, 106, 685-692. [CrossRef] [PubMed]

37. El-Zimaity, H.M. Accurate Diagnosis of Helicobacter pylori with Biopsy. Gastroenterol. Clin. North Am. 2000, $29,863-869$. [CrossRef]

38. Asano, K.; Kubo, M.; Yonemoto, K.; Doi, Y.; Ninomiya, T.; Tanizaki, Y.; Arima, H.; Shirota, T.; Matsumoto, T.; Iida, M.; et al. Impact of serum total cholesterol on the incidence of gastric cancer in a population-based prospective study: The Hisayama study. Int. J. Cancer 2007, 122, 909-914. [CrossRef] 